\title{
Experience in Implementing Lean Technologies in the Field of Transport
}

\author{
Yu.V. Ustinova \\ Department of technology of storage and grain processing, \\ Institute for Biotechnology, Food and Chemical \\ Engineering, \\ Polzunov Altai State Technical University \\ Barnaul, Russia Federation \\ egorovaeyu@mail.ru
}

\author{
Yu.I. Dymova \\ Department of Quality Management \\ Kemerovo State University \\ Kemerovo, Russia Federation \\ irina.reznichenko@gmail.com
}

\author{
E.O. Ermolaeva \\ Department of Quality Management \\ Kemerovo State University \\ Kemerovo, Russia Federation \\ eeo38191@mail.ru
}

\begin{abstract}
In June 2018, the Kuzbass Production and Management System was launched, which is applicable to various fields of activity: from industry to state and municipal administration. The methodology of the state corporation Rosatom has already allowed to achieve tangible results. The program "START" allows you to simplify the process, reduce the time it takes to complete tasks, improve quality. It was motorists who became pioneers in the implementation of the federal program "Lean Region".
\end{abstract}

Keywords: lean manufacturing, process management, transport services

\section{INTRODUCTION}

The quality management system, if it is not improved in the future, will become unsuitable, so that this does not happen, one of the means and methods of quality management can be used. Ten years ago, the term "lean manufacturing" came to Russia. This happened simultaneously with the publication of Jim Woomek's book "Lean Thinking", i.e. "Lean thinking." Unaware people still stubbornly believe that this concept comes down solely to minimizing production losses. But this is not so. Today, lean manufacturing is widely known among the managers of our country. Many of them are moving towards the creation and integrated development of production systems. If you don't go into the name - and there are quite a few terms for defining lean production [1]: "kaizen", "lin", "Toyota" production system - it is important to understand that it is applicable to any enterprises: by type of production process, size and industry. In order to realize all the advantages of this method, the organization must mature. it should be a conscious need to increase efficiency. And this should be noticed by the top management of the organization.

It cannot be said that in our country there is a massive interest in lean manufacturing. In Russia, its principles began to be implemented, first of all, by large industrial companies operating on global ones; this is the only opportunity to provide their markets for competitiveness [2]. For companies such as Russian Aluminum and Severstal, the implementation of lean manufacturing was not a voluntary choice. They were simply forced to adopt such a concept. As for small and medium-sized enterprises, lean manufacturing allows them to ensure the competitiveness of the medium and long term. Typically, in Russia such companies are about 15 years old; they were built from scratch in the 1990s. When the 8 owner, being both the manager, began to "rise" above the daily routine and evaluate the development of companies strategically, he understood that the use of lean manufacturing tools would be a way out of a difficult situation. Lean manufacturing is the management that it should be. The leader should think about the effectiveness of his organization. I must learn how to make a product or produce a service in full and on time, efficiently, inexpensively and at the same time safely. If the organization is effective, then its employees realize their creative potential, direct it to improve products for the consumer and their production processes. The market, of course, can be inefficient, but only for a while. Such companies are doomed to lag.

rs, an increase in transport costs has been observed in the economy of the Russian Federation. Thus, the increase in the transport component in the cost of goods and services 
increased from $7 \%$ to $25-28 \%$. Currently, reducing transport costs is one of the main tasks of economic development, and the effectiveness of road transport depends on a large number of factors. These include factors associated with the organization of transportation, with the system of technical maintenance (MOT) and repair (R) of motor vehicles (ATS) sold in motor transport enterprises (ATP), operating conditions, as well as the level of prices for fuel, tires, energy and other material resources. However, under equal conditions and external factors, a lot depends on the level of consumer properties, quality indicators (reliability) of transport and technological vehicles, including automotive vehicles, and also, which should be noted especially, the adopted system of their maintenance and $\mathrm{P}$, the volume and quality of service services offered by the manufacturer and its dealers - auto centers (AC) and car service stations (STO). Indeed, the downtime in maintenance and repair and the quality of their implementation, safety, environmental friendliness and efficiency, as well as the costs of technical operation of vehicles depend on the adopted system for maintaining the performance of automatic telephone exchanges and the level of their service support. It is known that during the operation of a car, the technical condition of its parts, components, systems and assemblies gradually deteriorates: fasteners are weakened, gaps in interfaces increase due to wear, throughput of nozzles, tubes, etc. decreases, physicochemical parameters change properties of lubricants and technical fluids, the accumulation of harmful deposits, corrosion and metal fatigue appear. The deterioration of the technical condition, in turn, adversely affects the consumer and operational qualities of automatic telephone exchanges: dynamism, fuel economy, reliability (failure-free), safety, comfort, environmental friendliness, etc.

To prevent and alleviate the above phenomena, preventive (diagnosis (D) and maintenance) and restoration (current, medium and overhaul) operations and optimization of maintenance (R) modes are required, which implies conducting research and monitoring of the automatic telephone exchange in operation in order to develop substantiated recommendations on the volume (content) of work, the complexity and frequency of their implementation; study of the influence of operating conditions on the technical condition of automatic telephone exchanges and the development of methods for adjusting maintenance modes in order to take into account their diversity in order to optimize the cost of maintaining vehicles in working condition. In other words, a sound system and maintenance regimes and $\mathrm{P}$ are necessary; without this, a rational and productive organization of the technical operation of cars is impossible. Moreover, the TO (P) modes, i.e. lists of work, their complexity and frequency of implementation are the most important elements of the system for maintaining the operability of automatic telephone exchanges, since the costs of maintenance and maintenance are largely determined by them. In addition, the need for posts for maintenance and TR, labor, maintenance materials and equipment depends on them. Finally, the qualifications and specialties of repair workers, the type and quantity of equipment used, the planning decisions of posts and lines, as well as the technology and organization of the production process of motor transport enterprises, auto centers and car service stations, depend on the content (list) of maintenance $(\mathrm{R})$ operations.

It should be noted that in recent years there have been significant changes in the design of automatic telephone exchanges, self-regulating mechanisms have appeared, the quality of the materials and lubricants used has improved, as well as the protection of friction units from dust, dirt and moisture. Therefore, in order to optimize the cost of technical operation, constant adjustment of the maintenance and $\mathrm{P}$ modes of vehicles is necessary. For example, the appointment of more favorable lubrication regimes and the rationale for the rational periodicity of oil changes in the units are important tasks, as they reduce the costs and expenses of lubricants, the complexity of lubrication, downtime in maintenance and the negative impact of PBX operating products (spent oils and special fluids) on the ecology.

\section{OBJECTS AND Methods OF RESEARCH}

The studies were conducted at the enterprise AnzheroSudzhenskoye GPATP KO. The main activity of the organization is automobile urban, suburban, intercity passenger transportation. As an experimental site, a passenger motor transport enterprise was chosen. As an experimental site, a passenger motor transport enterprise was chosen. The results of production optimization there exceeded all expectations. For example, in less than a year, the diagnosis of bus malfunctions was reduced from two hours to 10 minutes. The purpose of the study is the introduction of lean production on the example of the State Passenger Motor Transport Enterprise of the Kemerovo Region. Within the framework of the goal, the following tasks were set: - to conduct a preproject study, to study the types of losses in the organization providing motor services. - apply the concept of lean production on the example of Anzhero-Sudzhenskoye GPATP $\mathrm{KO}$.

\section{RESULTS AND DISCUSSION}

In Kuzbass, the results of a joint work with Rosatom on the implementation of lean technologies for 2018 were summed up. 29 According to the decision of the Governor Sergey Tsivilev, from July 6, 2018 in the Kemerovo region a complex of projects "Lean Region" is being implemented. As a result of joint work with the state-owned company Rosatom, 184 projects are already being implemented, 55 of which were completed at the end of 2018. The projects covered the following areas: state and municipal administration (47 projects), healthcare (25 projects), industry (8 projects), housing and communal services and transport (15 projects), employment of the population (35 projects), provision of public services (11 projects in MFC), education (29 projects), social protection of the population, cultural and sports organizations (14 projects). Also in Kuzbass began to introduce lean manufacturing technologies in state and municipal passenger motor transport enterprises. Projects aimed at accelerating work processes and saving costs are being implemented in 22 enterprises. They transport residents of the region in 20 cities, 36 district villages and about 600 rural settlements. Lean manufacturing (from the English lean production, lean manufacturing - "lean manufacturing") is the 
concept of managing a manufacturing enterprise based on a constant desire to eliminate all types of losses. Lean manufacturing involves involving every employee in the process and focusing on the consumer.

The project "Optimization of production processes in the maintenance and repair of cars" was developed. It is assumed that this will help reduce the time by two hours to search for a technical malfunction of the bus and put it on the post of maintenance or repair.

An optimization project for the second internal process is also proposed - "Improving the processes of driver documentation using contactless cards". It is divided into three subprojects: improving travel and ticket accounting records, reducing driver training for working and resting, and optimizing work when vehicles leave the line. This helped halve the time that experts spent on collecting and processing information on waybills, planning maintenance, purchasing tires - from 21 hours 45 minutes to 12 hours 40 minutes. It is planned to achieve such results, first of all, due to the automation of many processes. The preparation of documents and accounting are performed not manually, but with the help of special programs. Almost 22 hours earlier it took to compose an order for conductors, issue ticket-registration sheets, plan repairs, register and record fuel consumption. A project on the topic "Optimization of the work of a dispatcher, technician and chief engineer" was implemented at the auto enterprise. Automation of processes helped to reduce the processing time of documents from 15 hours 45 minutes to 1 hour 10 minutes. How did you achieve such time savings? Automation of the processes made it possible to abandon manual entry of data on mileage, reduce the time for compiling a schedule, and refuse to manually fill in the registration cards for tires. Also, buses began to be equipped with fuel level control sensors, which saves "diesel fuel" in a small PATP of 5-6 thousand liters. Given the dynamics of fuel prices, this is a serious result. And in the convoy 1237, this savings amounted to 25 thousand liters per month. The cost of one liter of fuel for the enterprise is about 40 rubles, so it turns out to save 1 million per month. True, not all drivers were delighted with the installation of sensors. It got to the point that they did not turn off the engines, leaving for lunch, did not turn off the stoves, and did much more so as not to show fuel economy. Fuel level monitoring is automatic; the sensor readings are processed by a special program. Consumption is displayed in a graph in real time.

Public transport has now begun to be equipped with CCTV cameras. This measure is designed to eliminate the facts of the passage of passengers without tickets, unplanned stops and helps to control the safety of both drivers and passengers. Thanks to the video recording system, ticket sales fees increase by $6-8 \%$. The passenger metering system allows you to control passenger flow to optimize the amount of transport on the routes. Currently, such a system is not installed on all vehicles, it requires significant funding, therefore, its implementation is being carried out in stages.

The task of introducing lean production in convoys is to improve the quality of passenger service, reduce costs and bring enterprises to profit. In turn, this will reduce budget costs for transport enterprises. Now it is already possible to consolidate the accumulated experience and gradually begin to replicate all decisions. Another question is that all this requires certain costs, but the savings will help enterprises in this. Technologies that are designed to improve and optimize, as a rule, have.

\section{REFERENCES}

[1] M. M. Salleh and M. Z. M. Zain, "The Study of Lean Layout in an Automotive Parts Manufacturer", MECHANICAL AND AEROSPACE ENGINEERING, PTS 1-7, Book Series: Applied Mechanics and Materials, 2012, Vol. 110-116, pp. 3947-3951, doi: 10.4028/www.scientific.net/AMM.110-116.3947.

[2] A.A. Akhramovich, E.V. Borisova, S.A. Odinokov, "Lean Manufacturing in Russia: Myth or Reality?", Proceedings of the 2017 International Conference Quality Management,Transport and Information Security, Information Technologies (It\&Qm\&Is), 2017, pp. 10-414.

[3] P. Knechtges, C.J. Bell and P. Nagy, "Utilizing the 5S Methodology for Radiology Workstation Design: Applying Lean Process Improvement Methods", Journal of the American College of Radiology, 2013, Vol. 10, Issue 8, pp. 633-634, doi: 10.1016/j.jacr.2013.05.001.

[4] C. Jaca, E. Viles, L. Paipa-Galeano, J. Santos and R. Mateo, "Learning $5 S$ principles from Japanese best practitioners: case studies of five manufacturing companies", International Journal of Production Research, 2014, Vol. 52, Issue 15, pp. 4574-4586, doi: 10.1080 / 00207543.2013 .878481 .

[5] P. Otenslegrova and F. Martinez, "From 5s Methodology to Lean Layout: Evidence from Automobile Industry", 12th International Days of Statistics and Economics, Sep. 06-08, 2018, pp. 1296-1305.

[6] J. Parnaby, "A Systems-Approach to the Implementation of JIT Methodologies in Lucas-Industries ", International Journal of Production Research, 1988, Vol. 26, Issue 3, pp. 483-492, doi: 10.1080/00207548808947878.

[7] M.N. Che-Ani, S. Kamaruddin and I. A. Azid, "Towards Just-in-Time (JIT) Production System Through Enhancing Part Preparation Process", 2017 IEEE INTERNATIONAL CONFERENCE ON INDUSTRIAL ENGINEERING AND ENGINEERING MANAGEMENT (IEEM) Book Series: International Conference on Industrial Engineering and Engineering Management IEEM, 2017, pp. 669-673.

[8] S. Shaaban, A.S. Darwish, "Production systems: successful applications and new challenges part one - lean, six sigma, inventory, JIT and TOC INTRODUCTION", Production Planning \& Control, 2016, Vol. 27, Issue 7-8, Special Issue SI, pp. 539-540, doi: 10.1080 / 09537287.2016.1165309. 